\section{Michael Chissick}

is head of the IT and OnLine Law Group at Field Fisher Waterhouse. He advises clients ranging from IT consultants, Internet service providers and companies providing IT systems and launching e-commerce sites.

Jan Radler

is a solicitor with Field Fisher Waterhouse with three years postqualification experience. He advises a number of large IT users and suppliers. His most recent experience involved advising on the implementation of a system delivering digital television on fibre-optic cables and assisting several companies setting up entirely Internetbased business.

\section{Recognition of digital signatures is key to secure electronic transactions}

\title{
Legal and Regulatory Update E-commerce policy developments
}

\author{
Michael Chissick and Jan Radler
}

Date received (in revised form): 28 July 1999

\section{Introduction}

The increasing importance of the developing virtual electronic market has been accompanied by a growing awareness of the difficulties in applying traditional legal concepts to this new environment. Proposals are being made on a national, international and European level to address various issues, particularly the legal and practical aspects of electronic commerce such as the security and legality of e-commerce transactions. The EU has made several proposals for directives and new legislation to cover issues such as electronic signatures, e-commerce and digital copyright.

\section{Requirements of secure electronic transactions}

Technology has lead to the development of new information infrastructure and 'open' networks, such as the Internet. This has enabled a truly global electronic trading infrastructure. The proliferation of business applications for these open, non-proprietary networks holds the promise of a new platform for inexpensive global communication and electronic commerce. Electronic trading has been valued at US $\$ 12$ bn per year worldwide, expected to increase to $\$ 350$ bn by $2002 .{ }^{1}$ Among the most significant barriers to the rapid expansion of the developing global electronic marketplace is the need to create a secure and trusted environment for electronic commercial transactions. As the growth of the number and volume of electronic transactions increases, the importance of security and reducing the risk of fraud and unauthorised access will also increase significantly. ${ }^{2}$

Security systems for commercial transactions have long been developed and implemented by businesses trying to raise the level of trust and confidence in commercial transactions. Except for cash-based systems, where funds are exchanged in an immediately available form, the existing credit and debit systems usually require disclosure of an individual's name and other identifiers, such as a credit card number supported by a signature that is unique to a person and difficult to imitate. The information is required for the purpose of identification and representation of authority to tender with credit or debit instructions, which are recognised by a third party, ie a bank that issued the credit or debit card. The virtual world of electronic transactions seeks to imitate this real-world standard. Digital signatures are proposed to take the place of real-world hand-written signatures. The virtual world also acknowledges the requirement of keeping personal details and identifiers confidential by seeking to prevent the unauthorised disclosure through methods of encryption. 
Chissick and Radler

\section{Public key cryptography and digital signatures}

Using this technology, senders and receivers of electronic messages each possess two keys (a public key and a private key), one of which is never shared with anybody, and the other of which is shared with everyone by publishing it to the world at large. These two keys correspond to each other, so that whatever is encoded with one key can only be decoded by the other. In the encrypting process, the sender of the message encodes it with the recipient's public key (which has been shared with him and all other parties), making it impossible for any party other than the one holding the private key to decrypt the message. Encryption protects the message from all parties other than the recipient, without the recipient having to divulge his private key to the sender. ${ }^{3}$

By reversing the process described above, public key cryptography also provides a highly dependable mechanism known as 'digital signature'. This digital signature is an attachment to a set of data. A digital signature can only be decrypted if the recipient has the correct public key, allowing the recipient to verify the identity of the sender. In a given transaction, therefore, the sender encrypts the message with the public key of the recipient and digitally signs or secures the message with his own private key and the recipient uses his private key to decrypt the message and the public key of the sender to verify the message's sender. ${ }^{4}$

Public key cryptography (PKC) is not suitable for encrypting long e-mail messages since the task of encryption and decryption would take too long. Long public key encrypted messages could be vulnerable to cryptographic attack, but a short message such as a 2048-bit key is totally secure. PKC is used as a method to communicate a conventional symmetrical key to be used by both parties when encrypting and decrypting, using an algorithm such as the Data Encryption Standard adopted by the US National Institution of Standards and Technology in $1976 .^{5}$

The most popular encryption program is called Pretty Good Privacy (PGP). It uses IDEA ${ }^{6}$ for data encryption, $\mathrm{RSA}^{7}$ for key management and $\mathrm{MD}^{8}$ as a one-way hash function.

Public key encryption assures two things for commercial transactions:

- that the messages are secure; and

- that the other transacting parties are authenticated.

\section{Written records are traditionally used to protect against fraud}

\section{Writing}

Traditionally, commercial transactions favoured written formal documentation and discouraged reliance on oral agreements to address the potential threat of fraud and dishonesty in commercial transactions. ${ }^{9}$ The requirement for a written record of commercial transactions has also endured for regulatory purposes, such as taxation of value-added goods and services and Customs. Despite this traditional formality, documentation has not been required to the exclusion of all other evidence of a transaction or agreement. In the USA, where a requirement for writing exists for the sale of goods of a value over US\$100, writing is loosely defined. Under civil law regimes, writing is 
Acceptance of electronic records as reliable written evidence of a transaction

\section{Legal recognition of electronic records}

merely treated as better evidence than the lack of writing. However, applying paper-based rules to electronic transactions without sufficient consideration of the ramifications of such rules increases uncertainty, working to the detriment of the international trading community. The dematerialisation of trade from the physical shop floor to the 'open' access network of the Internet required alternatives to the paper media on which trade data were traditionally communicated.

Therefore, worldwide message standards have been developed under the auspices of the UN. In December 1996, the UN Commission on International Trade Law adopted a Model Law on Electronic Commerce. ${ }^{10}$ The UNCITRAL Model Law is supported by a document produced by the International Chamber of Commerce Information Security Working Party as an ongoing project, the General Usage for International Digitally Ensured Commerce (GUIDEC).

The UNCITRAL Model Law treats electronic signatures as they relate generally to problems deriving from form requirements in existing commercial laws of the major legal systems. Specifically, the UNCITRAL Model Law provides that form requirements relating to signatures may be met in relation to data messages where a method is used that identifies the person and indicates that person's approval of the contents of the data message, and where the reliability of the method of signing is appropriate under the circumstances. ${ }^{11}$ The Draft Guide to the UNCITRAL Model Law indicates that it may be useful to develop functional equivalents for the various types and levels of signature requirements in existence. The UNCITRAL Model Law treats signature requirements (in the context of the evidential weight of data messages) depending on the reliability of the manner in which the data message was generated, stored, communicated and maintained in general.

In a meeting of the EU's Telecommunications Council on 22 April 1999, agreement was reached on the proposal for a directive for electronic signatures. The proposed directive is intended to harmonise the legal framework for the use of electronic signatures throughout the EU. It will regulate both the legal effect of signing a document with an electronic signature and the provision of an electronic signature. The draft directive provides that electronic signatures are not to be denied legal effect, validity or enforceability solely on the ground that they are in electronic form. An electronic signature should be considered equivalent to a hand-written signature in any legal proceedings if it is an 'advanced electronic signature'. To qualify as an advanced electronic signature it must be uniquely linked to the signatory, be capable of identifying the signatory, be created using means that the signatory can maintain under her/his sole control and be linked to the data to which it relates in such a manner that any subsequent change of the data is detectable. The signature must also be confirmed by a qualified certificate, and must be created using a 'secure signature creation device' meeting criteria of reliability set out in an appendix to the directive.

On 5 March 1999, the DTI and the Home Office published a consultation paper aimed at 'promoting electronic commerce'. ${ }^{12}$ The 
Chissick and Radler

\section{Verification of digital signatures and encryption keys by trusted intermediaries}

government intends to update laws to afford legal recognition to electronic instruments and, in particular, electronic signatures. There are plans to make traditional and electronic means of communication equally valid. As long as an electronic signature meets certain conditions and correctly identifies the signatory, guaranteeing that the accompanying data have not been altered since signature, that will be sufficient proof of authenticity. This a 'rebuttable presumption' and will require proof to the contrary. Careful thought is needed about whether 'a rebuttable presumption' would satisfy the EU proposal that electronic signatures are not to be denied legal effect and in what form the EU final directive will address the issue of fraud.

\section{Trusted third parties}

The use of public key cryptography for digital signatures requires that a trusted third party establishes that holders of public keys are indeed who they claim to be. Without a trusted third party's verification that a given individual is the holder of a public key, it is impossible for other transacting parties on the network to know for certain that the holder of the public key is not an impostor. This third party, commonly known as a Certification Authority, will form the trust backbone for all types of commercial and non-commercial transactions taking place over open networks. Certification Authorities will confirm the identity of the public key holder and publish and update the public keys. The effectiveness of this process depends upon establishing Certification Authorities to provide parties with a reliable means of linking the public and private key pair with an identified person and a trustworthy means of ascertaining the public key needed for verification. Given the importance of the accuracy of the information provided by the trusted third party, the certifier must be sufficiently trustworthy to assure a high level of trust in electronic commercial transactions.

The proposed EU directive will prevent member states from requiring prior authorisation of certification service providers (CSPs). However, it will allow member states to introduce their own voluntary accreditation schemes aimed at enhancing levels of certification service. Under the directive, every CSP will be required to meet certain standards of reliability and security, such as having personnel with expert knowledge, a prompt and secure revocation service and use of trustworthy systems. The certificates issued by such a CSP must state the identity of the CSP, the name of the signatory or a clearly identifiable pseudonym, confirmation of the corresponding public key and any limitations on the scope or validity of the certificate.

The draft EU directive provides that CSPs should be liable to any party who relies on a qualified certificate for the accuracy of the information in the certificate. The CSP may limit its liability either by stating on the certificate the uses for which it may be relied upon and/or by placing a limit in on the value of the transaction for which the certificate is valid. In addition, the CSP cannot be held liable for errors in information contained in the certificate which were provided by the signatory, provided the CSP took 'all reasonably practicable measures' to verify that information. 


\section{Additional formalities for consumer contracts formed on the Internet}

\section{The Distance Selling Directive}

The aim of the Distance Selling Directive (DSD) was to protect consumers against some of the risks of ordering goods when not face to face with the retailer, for example over the Internet. Although it was not specifically intended to apply to the Internet, the DSD will have a considerable impact on the trading between businesses and consumers on the Internet. The DSD was adopted by the European Parliament and Council in May 1997 and will have to be implemented by all member states by 4 June 2000 .

The implementation of the DSD ${ }^{13}$ will result in the communication and recording of additional detailed information about the contract and the terms and conditions of a consumer transactions ${ }^{14}$ and payments by card. ${ }^{15}$ The DSD was not drafted exclusively for the Internet, but it is the first legislation which recognises significant features of e-commerce as a form of distance selling. Essentially, the DSD covers five main areas: the provision of information about the contract and its terms (Articles 4 and 5); the right of withdrawal (Article 6); the obligations as to performance by the supplier (Article 7); payment by card (Article 8); and inertia selling (Article 9).

Article 4 of the DSD, covering the provision of information about the contract and the terms and conditions, specifies that before the conclusion of any distance contract (remembering that conclusion of a contract may occur before the performance of all obligations) the consumer must be provided with the following information:

- the identity of the supplier and, in the case of contracts requiring payment in advance, his/her address;

- the main characteristics of the goods or services;

- the price of the goods or services including all taxes;

- delivery costs, where appropriate;

- the arrangements for payment, delivery or performance;

- the existence of a right of withdrawal, except in certain cases specified in the Article where this right does not exist;

- the cost of using the means of distant communication, where it is calculated other than at the basic rate;

- the period for which the offer or the price remains valid; and

- where appropriate, the minimum duration of the contract in the case of contracts for the supply of products or services to be performed permanently or recurrently.

The information must be provided in a way appropriate to the means of distance communication with due regard to the principles of good faith ${ }^{16}$ in commercial contracts and the rules for protection of vulnerable people, such as minors.

The essential requirement for conducting secure electronic transactions over the Internet will be the certification and identification of the individuals conducting the trade. This will be done by sending data messages which either contain the personal data, such as name, address and credit card number, or personal identifiers, such as digital 
Chissick and Radler

\section{EU seeks to address legal uncertainties of electronic transactions}

signatures and public encryption keys, by which reference personal data may be ascertained from certifying trusted third parties.

\section{Proposed EU E-Commerce Directive}

On 18 November 1998, the European Commission announced 'a proposal for a European Parliament and Council Directive on certain legal aspects of electronic commerce in the Internal Market' with the aim of ensuring 'the proper functioning of the internal market, particularly the free movement of Information Society services between the Member States'. The E-Commerce Directive (ECD) is intended to complement Community law applicable to information society services without prejudice to the existing level of protection for public health and consumer interests, as established by Community legislation. The ECD will apply to all information society services, including online services, whether business to business or business to consumer, and services allowing for electronic transactions such as online shopping malls.

The proposed ECD addresses one of the main uncertainties of electronic transactions, namely, when and how contracts are concluded online and what legal factors are restraining the process of contracting online. The ECD obliges member states to adjust their national legislation to lift any prohibitions or restrictions on the use of electronic media for concluding contracts and seeks to clarify when such contracts may be concluded. ${ }^{17}$ This is not something which is being addressed specifically as part of the UK government's proposal for the E-Commerce Bill. The consultation document contains a section on 'legal recognition of electronic signatures', looking at electronic signatures and electronic writing. ${ }^{18}$ It does not really address contract issues as such, but concentrates more on the validity of digital signatures.

The proposed ECD also seeks to remove current legal uncertainty and ensure that operators cannot evade supervision, as they would be subject to supervision in the member state where they were 'established'. The responsibility of online service providers for transmitting and storing information from third parties (ie when they are acting as 'intermediaries') will be clarified. The proposal establishes an exemption from liability for intermediaries where they play a passive role as a 'mere conduit' and would limit their liability for other 'intermediary activities' such as storage of information, for example hosting a website and 'caching'. ${ }^{19}$

\section{UK proposal for an E-Commerce Bill}

The UK government intends to introduce the E-Commerce Bill (ECB) to build confidence in electronic commerce and the underlying technology. The UK government will achieve these objectives by providing for:

- a statutory approvals scheme for business and other organisations providing cryptography services, such as electronic signature services and confidentiality services;

— the legal recognition of electronic signatures; and 
- the removal of obstacles in other legislation to the use of electronic communication storage in place of paper.

Unlike the ECD, the ECB does not seek to address the wider legal uncertainties of electronic commerce.

\section{UNCITRAL Model Law}

The underlying policies set out in the UNCITRAL Model Law and the GUIDEC are seen as vital in addressing the issue of security and public confidence in the electronic business environment. These include:

- enhancing the ability of the international business community to execute secure digital transactions;

- establishing legal principles that promote trustworthy and reliable digital ensuring and certification practices;

- encouraging the development of trustworthy ensuring and certification systems;

- protecting users of the digital information infrastructure from fraud and errors;

- balancing security and certification technologies with existing policies, laws, customs and practices;

- defining and clarifying the duties of participants in the emerging ensuring and certification system; and

- fostering global awareness of developments in ensuring and certification technology and its relationship to secure electronic commerce.

\section{Conclusion}

The national, international and Europe-wide proposals have all identified the need for legislative intervention. The present legal

Existing national formalities create barriers for global electronic trading

\section{Suppliers responsibilities for goods sold electronically} framework, even in countries like the USA and Singapore which have laws specifically recognising e-commerce, suffers from legal barriers created by existing formality requirements and the limitation of territorial boundaries. The ECD appears to address the current uncertainties over the formation of electronic contracts and enforceability. However, the ECD allows the EU member states considerable flexibility regarding its implementation. This means that although it may relieve the uncertainty over enforceability of the contracts, it fails to achieve a standardisation of electronic transactions, even within the EU.

One of the main uncertainties and, therefore, risks is the different legal treatment of liabilities and rights in respect of defects in goods or services provided over the Internet. While it may be seen as encouraging that the EU Commission appears to promote a 'European standard', critics have suggested that such a standard may act as an impediment to governments enacting laws that promote seamless electronic commerce across all borders. ${ }^{20}$

The electronic environment facilitates a seemingly unlimited ability to send and transmit information across boundaries irrespective of the legal 


\section{Legal frameworks need to be global}

frameworks that may seek to control access to it, but it requires the legal and regulatory framework to address the commercial issues at stake. Every electronic transaction potentially involves intellectual property rights (trademarks and copyright), security and payment mechanisms, distance selling, data protection and jurisdictional and applicability of law conflicts. This requires careful analysis of the full impact of each proposed piece of legislation on other legislative proposals and also on existing legislation, so that the legal framework does not continue to create artificial boundaries to the Internet marketplace.

\section{References}

1. Rowe, H. (1999) 'E-commerce Policy Developments in the UK and the EU', Computers and Law, Vol. 10, No. 2, p. 21

2. GUIDEC, ICC, 11 May 1999, p. 9

3. Ibid., p. 11.

4. Ibid.

5. Chissick, H. and Kelman, A. (1998) Electronic Commerce Law and Practice, Sweet and Maxwell, p. 129

6. International Data Encryption Algorithm

7. Invented by Rivest, Shamir, Adleman

8. Invented by Ron Rivest at MIT in 1991.

9. Statute of Frauds embodied in US law in UCC Article 2-201, or originally in s. 40, Law of Property Act 1925, now to be found in s. 2 of the Law of Property (Miscellaneous Provisions) Act 1989

10. UNCITRAL Model Law, at http://www.un.or.at/uncitral/english/texts/electcom/ml.ec.htm

11. Ibid., Article 6.

12. Consultation on Draft Legislation and the Government's Response to the Trade and Industry Committee's Report, Cm4417, 5 March 1999.

13. Directive $97 / 7$ EC

14. Ibid., Articles 4 and 5 .

15. Ibid., Article 8.

16. This is a civil law concept, which, not being a recognised legal doctrine in the common law tradition, may be difficult to implement in the UK legislation.

17. COM (1998) 586 Final, 98/0325, Article 9.

18. Consultation on Draft Legislation and the Government's Response to the Trade and Industry Committee's Report, Cm4417, 5 March 1999, Part II.

19. Stokes, S. (1999) 'European Commission Proposes E-commerce Directive', Electronic Business Law, Vol. 1, No. 1.

20. Rowe, ref. 1, p. 25. 